\title{
Making A Difference
}

\author{
Marvin L. Birnbaum, MD, PhD
}

Today is not yesterday;
We, ourselves change;
How can our Works and Thoughts
if they are always to be fittest,
Continue always the same?
Change, indeed, is painful; Yet, ever needful;
And, if Memory has its force and worth, so also is hope.

Carlyle, Essays, Characteristics

They must often change who would be constant in bappiness and wisdom

Confusius; Goldsmith, Citizens of the World. No. 13

As we enter Volume 20 of Prehospital and Disaster Medicine (PDM), many important advances have been implemented or are about to occur. What follows is a brief summary of what we are doing to make your Journal even better.

First, and of the greatest significance, as of January 2005, PDM will be published bimonthly (January, March, May, July, September, and November). Thanks to all of you who view PDM as the vehicle to share your important work, we now have material sufficient in quality and number to fill six issues per year with valuable, peer-reviewed information relevant to the practice of prehospital, emergency, disaster, and humanitarian medicine.

In addition, significant changes have occurred in the Editorial Office during the last year. The staff, led by Wendy Dopkin, has made great strides in processing manuscripts, and now, has decreased the turnaround time for manuscripts submitted for review and publication. Thanks to the excellent work of the staff and of the reviewers returning their reviews in very short times, most papers now are being published within six months or less of receipt for review. This will be facilitated further by moving to bimonthly publication. The only delays in this process now are related to the authors turning around their revisions.

As many of you are aware, the Editorial Staff is willing to assist you in the preparation of your manuscripts and for revision of manuscripts accepted for publication pending revision. Also, as a reminder, manuscripts submitted for review and publication must be in the format outlined in the Instructions to Authors provided in each issue of PDM.
You have been noticing that an increasing number of articles are being followed by Editorial Comments that stress the most important aspects of the work and its significance to our practice, and suggest improvements that can be incorporated into future efforts. This readerrequested aspect of the Journal is being led by Dr. Samuel Stratton of the University of California-Irvine.

Thanks to the extraordinary efforts of Graciela Zapata and several of her co-workers, PDM now publishes the abstracts of all of the papers in Spanish as well as in English. Furthermore, the same persons have provided a complete translation into Spanish of Volume 1 of the Health Disaster Management: Guidelines for Evaluation and Research in the Utstein Style, which is being typeset currently and will be printed early this year with the cooperation of the Pan-American Health Organization/World Health Organization (PAHO/ WHO). In addition, Zapata and her coworkers, led by Dr. Felipe Cruz-Vega, have agreed to translate the full text of articles that have special interest to health professionals in Latin America and the Caribbean into Spanish. These translated arricles will be posted on the PDM website. As you are aware, we already have published many documents that have importance to our practice from the $\mathrm{PAHO} / \mathrm{WHO}$ in both English and Spanish.

On your suggestion, we have replaced the contents box on the cover with contemporary artwork. We have enjoyed this change and look forward to those of you who have expertise in the arts to submit your work for review and publication.

The composition of the Editorial Board also has been changing to further reflect the direction of the Journal. We have included persons with the special expertise required for the continued progression of the science of prehospital, emergency, disaster, and humanitarian medical care. We have broadened the expertise available to us from the panel of professionals who provide the Editorial Board and staff with competent reviews of the manuscripts submitted. They have agreed to provide rapid turnaround for their reviews that will allow us to shorten the time from receipt to publication of your important work. The revamped Editorial Board will meet at the 14th World Congress for Disaster and Emergency Medicine to be convened in Edinburgh in May. If you have any suggestions to improve your 
Journal, please forward them to any member of the Editorial Board or to the Editorial Office.

We have had great responses from you pursuant to the Special Theme Issues published in the recent volumes. Several more will be published in the near future including a practical guide to missions into disaster areas, a survey of Emergency Medical Services Systems (EMS) worldwide, and another that will identify current issues in international EMS.

Volume 2 (Operational Framework) and Volume 3 (Research and Evaluation Methodologies) of the Health Disaster Management: Guidelines for Evaluation and Research in the Utstein Style, will be published in English as Supplements later this year and will be followed shortly thereafter in Spanish. Volume 1 (Conceptual Framework) also is being translated into Japanese.

Lastly, there have been substantive upgrades in the PDM website. There have been more than 50,000 queries of the PDM website since its inception in May 1999. The number of searches has grown progressively and now averages 50 hits/day. Persons from 138 different countries have accessed our website. All of the manuscripts to be published in the printed issue are posted on the website 3-4 weeks before the printed version is mailed and are accessible to subscribers. The two most recent issues are password protected for the PDM subscribers. The complete contents in full text in pdf format of all issues starting with Volume 17 (2002) are readily accessible to all interested from the PDM homepage without charge. Furthermore, a new PDM Search Engine currently is being tested that not only will scan the abstracts and keywords, but will parse all of the pdf files that contain full text. By the time you read this, this search engine should be active. Try it and forward your comments to us. In addition, more effort is being directed to the Reference Clearing House section on the website. It is an objective of this project to make all information referenced by the authors published in PDM accessible through its own search engine. The search will include authors, words or phrases included in the title, keywords, and $\mathrm{MeSH}$ headings. This feature should facilitate your access to relevant literature. When available, the abstracts and in some instances, the full texts for those references that are available through MedLine will be accessible directly from the website.

Thanks to those of you who have used and contributed to the growth of PDM for your support and we look forward to your helping us build the science of prehospital, emergency, disaster, and humanitarian medicine. Your dedication to our cause is exceptional and we hope we can continue to meet your expectations. As always, we look forward to suggestions on how we can enhance our services to you (pdm@medicine.wisc.edu).

There is danger in reckless change; but greater danger in blind conservatism.

Henry George, Social Problems

Thus, times do shift; each thing bis turn does bold. New things succeed as former things grow old.

Herrick, Ceremonies for Candlemas Eve 